\title{
Control of Helical Chirality of Ferrocene- Dipeptide Conjugates by the Secondary Structure of Dipeptide Chains
}

\author{
Toshiyuki Moriuchi, Taiki Nishiyama, Masaki Nobu, \\ Toshikazu Hirao
}

\begin{tabular}{|c|l|}
\hline Citation & Chemistry - A European Journal, 23(52): 12704-12708 \\
\hline Issue Date & $2017-09-18$ \\
\hline Type & Journal Article \\
\hline Textversion & Author \\
\hline $\begin{array}{c}\text { Supporting } \\
\text { information }\end{array}$ & Supporting information is available at https://doi.org/10.1002/chem.201703102 \\
\hline & $\begin{array}{l}\text { This is the peer reviewed version of the following article: MORIUCHI, T., } \\
\text { NISHIYAMA, T., NOBU, M., \& HIRAO, T. (2017). Control of Helical Chirality of } \\
\text { Fights } \\
\text { Ferrocene-Dipeptide Conjugates by the Secondary Structure of Dipeptide Chains. } \\
\text { Chemistry - A European Journal. 23, 12704-12708., which has been published in } \\
\text { final form at https://doi.org/10.1002/chem.201703102 . This article may be used for } \\
\text { non-commercial purposes in accordance with Wiley Terms and Conditions for } \\
\text { Self-Archiving. }\end{array}$ \\
\hline DOI & \begin{tabular}{l} 
10.1002/chem.201703102 \\
\hline
\end{tabular} \\
\hline
\end{tabular}

\author{
Self-Archiving by Author(s) \\ Placed on: Osaka City University
}

MORIUCHI, T., NISHIYAMA, T., NOBU, M., \& HIRAO, T. (2017). Control of Helical Chirality of Ferrocene-Dipeptide Conjugates by the Secondary Structure of Dipeptide Chains. Chemistry - A European Journal. 23, 12704-12708. 


\title{
Control of Helical Chirality of Ferrocene-Dipeptide Conjugates by the Secondary Structure of Dipeptide Chains**
}

\author{
Toshiyuki Moriuchi, * Taiki Nishiyama, Masaki Nobu, and Toshikazu Hirao*
}

\begin{abstract}
Controlling helical chirality and creating protein secondary structures in ferrocene-dipeptide bioorganometallic conjugates were achieved by adjusting the conformational flexibility of the dipeptide chains. In systems reported thus far, the helical chirality of a conjugate was determined by the absolute configuration of the adjacent amino acid reside. In contrast, it was possible to induce both $M$ - and P-helical chirality, even when the configuration of the adjacent amino acid was the same. It is particularly interesting to note that M-helical chirality was produced in a cyclic ferrocene-dipeptide conjugate composed of the L-Ala-D-Pro-cystamine-D-Pro-L-Ala dipeptide sequence (1), in which a type II $\beta$-turn-like secondary structure was established.
\end{abstract}

Short peptides are powerful motifs for designing chirality-organized molecular self-assemblies because of their directed hydrogen bonding interactions. In the field of bioorganometallic chemistry, ${ }^{[1]}$ ferrocene scaffolds conjugated with amino acids or short peptides have been employed as a model system for studies of protein folding, in which ferrocene serves as a central reverse-turn unit. ${ }^{[2]} \mathrm{We}$ previously reported that a series of ferrocene-dipeptide conjugates derived from 1,1'-ferrocenedicarboxylic acid can induce helical chirality through intramolecular hydrogen bonding of the dipeptide chains. ${ }^{[2 \mathrm{~g}, 3]}$ In these systems, the helical chirality that is induced depends solely on the absolute configuration of the $\alpha$-carbon atom of an amino acid adjacent to the ferrocene core. For example, when L-Ala is used as the adjacent amino acid, $P$-helical chirality is induced, irrespective of the absolute configuration of the second amino acid. As such, the induced helical chirality is determined by the absolute configuration of the adjacent amino acid, and no methods for controlling helical chirality without changing the structure of the adjacent amino acid are currently available. We report herein that conformational restriction can be used as a new controlling factor for inducing the helical chirality of ferrocenedipeptide conjugates. Both $P$ - and $M$-helical chirality can be induced by using an adjacent amino acid with the same absolute configuration.

We previously reported that $P$-helical chirality of ferrocenedipeptide conjugates derived from 1,1'-ferrocenedicarboxylic acid is

[*] Dr. T. Moriuchi, T. Nishiyama, M. Nobu Prof. Dr. T. Hirao Department of Applied Chemistry, Graduate School of Engineering, Osaka University

Yamada-oka, Suita, Osaka 565-0871 (Japan)

Fax: (+81) 6-6879-7415

E-mail: moriuchi@chem.eng.osaka-u.ac.jp hirao@chem.eng.osaka-u.ac.jp

[**] This work was supported partly by "JSPS KAKENHI Grant Number JP16H01024 in Precisely Designed Catalysts with Customized Scaffolding". Thanks are due to the Analytical Center, Graduate School of Engineering, Osaka University.

Supporting information for this article is given via a link at the end of the document. induced by hydrogen bonding interactions of the L-amino acids, which is similar to the antiparallel $\beta$-sheet structure found in proteins. ${ }^{[2 \mathrm{~g}, 3]}$ We envisioned that helical chirality might be inverted without changing the absolute configuration of the adjacent amino acids if an antiparallel $\beta$-sheet type structure can be altered to a different secondary structure by reorienting the hydrogen bonding interactions. One simple way to realize such a change in the secondary structure of dipeptides should be the introduction of a cyclic structure that could function to tie the terminals of dipeptide chains together. This cyclization would restrict the conformational flexibility of the dipeptide chains, thereby triggering the reordering of the hydrogen bonding. Although several cyclic ferrocene-peptide conjugates have been reported, ${ }^{[4]}$ inversion of the helical chirality was not observed in these systems, and only $P$-helical chirality is induced when L-amino acids are attached to the ferrocene core, which is a completely consistent with observations for acyclic systems. We concluded that a systematic investigation of the effect of a cyclic structure on induced chirality would be appropriate.

To this end, we employed cystamine $\left(\mathrm{H}_{2} \mathrm{NCH}_{2} \mathrm{CH}_{2} \mathrm{~S}\right.$ $\mathrm{SCH}_{2} \mathrm{CH}_{2} \mathrm{NH}_{2}$ ) as a linkage to cyclize two dipeptide chains attached to the ferrocene core, in hopes that the corresponding ring-opened derivatives could be readily accessed by the reductive cleavage of the disulfide bond to thiols. ${ }^{[5]}$ Our assumption was that the disulfide bond would serve as a chirality switching unit by changing the open/closed forms of ferrocene-dipeptide conjugates. Regarding the dipeptide chains, a heterochiral sequence such as L-Pro-D-Ala was reported to enforce a reverse-turn conformation in some designed oligopeptides. ${ }^{[6]}$ Based on this observation, we envisioned that introducing a heterochiral sequence to a ferrocene core might be used to form a reverse turn structure, when conformational flexibility is suitably restricted by the cyclic structure. With this hypothesis in mind, we designed the cyclic ferrocene-dipeptide conjugate $\mathbf{1}$, wherein the $\mathrm{C}$-terminals of the dipeptide chains are connected by cystamine. An L-Ala-D-Pro sequence was used as a heterochiral dipeptide chain because alanine is a smallest chiral amino acid and a sterically constrained proline would be expected to serve as a turn inducer. The corresponding cyclic ferrocenedipeptide conjugates $\mathbf{2}$ having a homochiral dipeptide sequence (i.e., L-Ala-L-Pro) were also synthesized to investigate the effect of the chirality of the remote amino acid on the induced helical chirality of the conjugates. Conjugates 1 and $\mathbf{2}$ were synthesized from 1,1'ferrocenedicarboxylic acid or 1,1'-bis(chlorocarbonyl)ferrocene and the corresponding dipeptide derivative (Figure 1), and were fully characterized by spectral data.

$\mathrm{X}$-ray crystal structure analyses were performed in order to clarify the chirality-organized structure (Figure 2). ${ }^{[7]}$ The molecular structure of 1 was characterized by the formation of intramolecular hydrogen bonds between the $\mathrm{NH}$ group of cystamine and the $\mathrm{CO}$ group of the ferrocenoyl moiety of each dipeptide chain $(\mathrm{N}(3) \bullet \bullet \mathrm{O}(1), 2.921(9) \AA ; \mathrm{N}(23) \cdots \bullet \mathrm{O}(21), 2.878(9) \AA)$ to create a $\beta$ turn-like structure in each dipeptide moiety. The torsion angles $\phi_{2}$ 


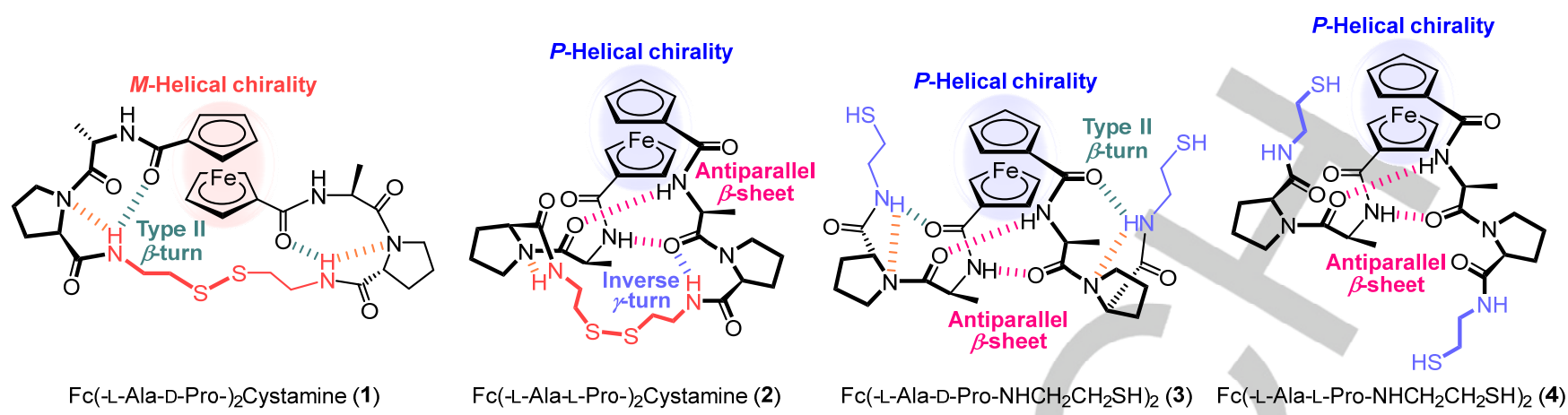

Figure 1. Designed ferrocene-dipeptide conjugates 1-4

(a)

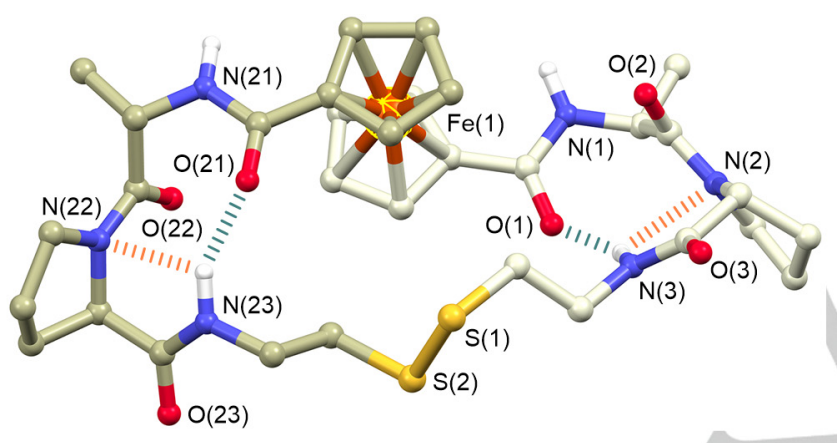

(b)

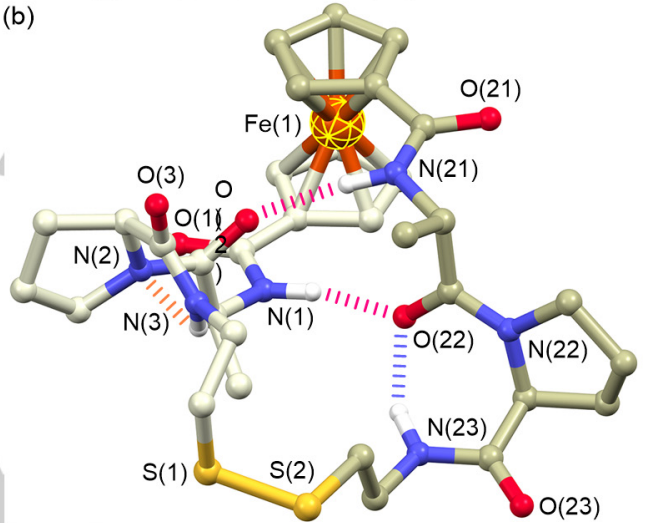

Figure 2. (a) Molecular structures of 1 and (b) 2 (hydrogen atoms, which are not involved in hydrogen bonding, are omitted for clarity). The dotted lines represent hydrogen bonds.

(a)<smiles></smiles>
top view<smiles></smiles>

(b)
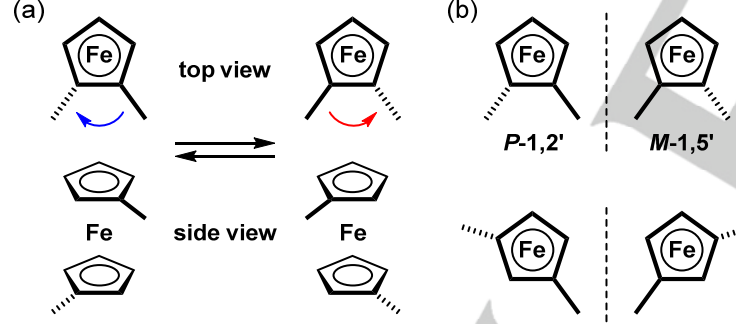

$P$-helical chirality
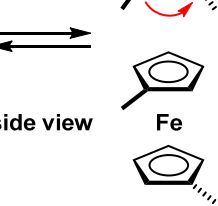

M-helical chirality
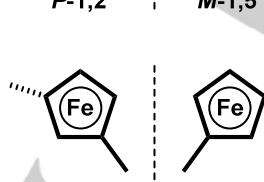

$P-1,3^{\prime}$

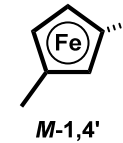

Figure 3. Schematic representation of 1, $n^{\prime}$-disubstituted ferrocenes. (a) Top and side views of $P$-helical chirality and $M$-helical chirality, respectively, and (b) stereoisomers of the axial chirality.

$\left(\phi_{2}=-66.5(8)^{\circ}\right.$ and $\left.\phi_{2}^{*}=-57.5(7)^{\circ}\right), \psi_{2}\left(\psi_{2}=136.1(6)^{\circ}\right.$ and $\psi_{2}^{*}=$ 141.1(6) $\left.{ }^{\circ}\right), \phi_{3}\left(\phi_{3}=81.9(8)^{\circ}\right.$ and $\left.\phi_{3} *=79.4(8)^{\circ}\right)$, and $\psi_{3}\left(\psi_{3}=\right.$ $3.7(9)^{\circ}$ and $\left.\psi 3^{*}=3.7(9)^{\circ}\right)$ of 1 suggest a type II $\beta$-turn-like structure despite $\phi_{2}=-60^{\circ}, \psi_{2}=120^{\circ}, \phi_{3}=80^{\circ}$, and $\psi_{3}=0^{\circ}$ for an ideal type II $\beta$-turn. This type II $\beta$-turn-like structure was found to be stabilized by intramolecular $\mathrm{N}-\mathrm{H} \cdot \cdots \mathrm{N}$ hydrogen bonding pattern between the $\mathrm{NH}$ of cystamine and the nitrogen of Pro $(\mathrm{N}(3) \cdots \cdot \mathrm{N}(2), 2.723(9) \AA$; $\mathrm{N}(23) \cdots \mathrm{N}(22), 2.714(8) \AA)$. Conformational enantiomers, $P$ - and $M$-helical conformations which are interconvertible, based on the presence of a torsional twist about the $\mathrm{Cp}$ (centroid)-Fe- $\mathrm{Cp}$ (centroid) axis in the 1, $n^{\prime}$-disubstituted ferrocene, as depicted in Figure 3. ${ }^{\text {[2-d,2f- }}$ g] The cyclic ferrocene-dipeptide conjugate $\mathbf{1}$ was found to adopt an $M$-helical chirality with an $M-1,4^{\prime}$ helical conformation of the

ferrocenoyl moiety, as shown in Figure 2a. Ferrocene-dipeptide conjugates composed of the L-Ala-L-Pro or the L-Ala-D-Pro dipeptide chains were reported to show $P$-helical chirality, wherein the chirality of the ferrocenoyl moiety is likely to be controlled by the chirality of the $\alpha$-carbon atom of alanine. ${ }^{[2 \mathrm{c}-\mathrm{d}, 2 \mathrm{f}-\mathrm{g}]}$ The formation of a type II $\beta$-turn-like structure induced $M$-helical chirality in the ferrocenoyl moiety in the cyclic conjugate 1. Each molecule is linked to four neighboring molecules by continuous intermolecular hydrogen bonds, wherein methanol solvent molecules play important roles as a hydrogen-bonding bridge in the crystal packing (Figure S1 in the Supporting Information). In contrast to the structure of $\mathbf{1}$, the molecular structure of the cyclic conjugate $\mathbf{2}$ composed of a homochiral dipeptide (L-Ala-L-Pro-cystamine-L-ProL-Ala) showed $P$-helical chirality with $P$-1,2' helical conformation of the ferrocenoyl moiety through the formation of intramolecular antiparallel $\beta$-sheet-like hydrogen bonds between the $\mathrm{NH}$ of Ala and the $\mathrm{CO}$ of Ala (another chain) of each dipeptide chain $(\mathrm{N}(1) \cdots \mathrm{O}(22)$, 2.958(14) $\AA$; $\mathrm{N}(21) \cdots \mathrm{O}(2), 2.981(18) \AA$ ) as depicted in Figure 2b. The induced chirality of the ferrocenoyl moiety was found to be controlled through a conformational conversion from a type II $\beta$ turn-like structure to an antiparallel $\beta$-sheet-like structure by changing the chirality of the prolyl moiety. Another interesting structural feature is the creation of a $\gamma$-turn-like structure through intramolecular hydrogen bonding between one of the $\mathrm{NH}$ of cystamine units and the $\mathrm{CO}$ of the Ala unit of same dipeptide chain $(\mathrm{N}(23) \cdots \mathrm{O}(22), 2.867(16) \AA)$. The torsion angles $\phi_{3}\left(-87.3(16)^{\circ}\right)$ and $\psi_{3}\left(61.6(15)^{\circ}\right)$ of 2 indicate an inverse $\gamma$-turn-like structure similar 
(a)

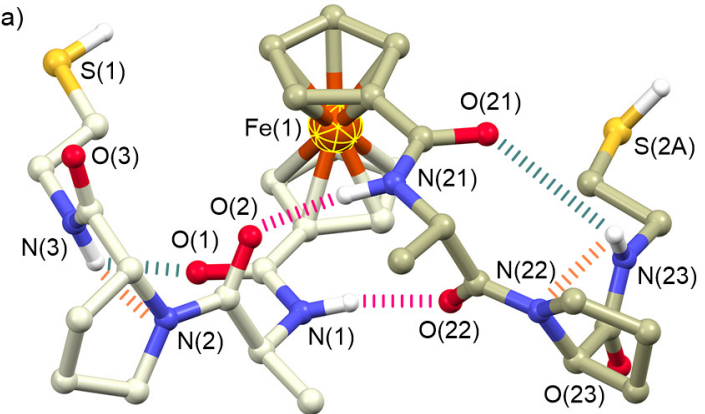

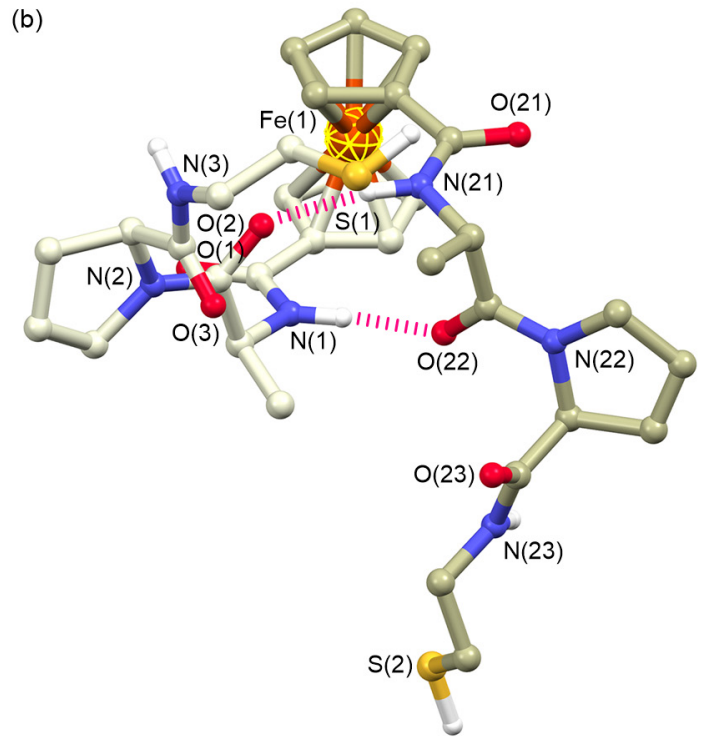

Figure 4. (a) Molecular structures of 3 and (b) $\mathbf{4}$ (hydrogen atoms, which are not involved in hydrogen bonding, are omitted for clarity). The dotted line represents the hydrogen bond.

to an ideal inverse $\gamma$-turn $\left(\phi_{3}=-70^{\circ}\right.$ and $\left.\psi_{3}=60^{\circ}\right)$. Another NH of cystamine participated in an intramolecular hydrogen bond with the nitrogen of Pro moiety $(\mathrm{N}(3) \cdot \bullet \mathrm{N}(2), 2.693(16) \AA)$.

To gain insights into the effect of the cyclic structure on the induction of helical chirality, the acyclic analogues 3 and $\mathbf{4}$ were synthesized by the reductive cleavage of disulfide bonds in cyclic conjugates $\mathbf{1}$ and $\mathbf{2}$. Thus, the reaction of cyclic conjugate 1 or 2 with $\mathrm{PBu}_{3}$ in the presence of methanol in THF led to the formation of the ring opened derivative 3 and 4 bearing two L-Ala-D-Pro- $\mathrm{NHCH}_{2} \mathrm{CH}_{2} \mathrm{SH}$ or L-Ala-L-Pro$\mathrm{NHCH}_{2} \mathrm{CH}_{2} \mathrm{SH}$ dipeptide chains, respectively (Figure 1). A single-crystal X-ray structure analysis of 3 bearing two L-AlaD-Pro- $\mathrm{NHCH}_{2} \mathrm{CH}_{2} \mathrm{SH}$ dipeptide chains confirmed that intramolecular antiparallel $\beta$-sheet-like hydrogen bonds were formed between the $\mathrm{NH}$ of $\mathrm{Ala}$ and the $\mathrm{CO}$ of Ala (another chain) of each dipeptide chain $(\mathrm{N}(1) \cdots \mathrm{O}(22), 2.946(10) \AA$; $\mathrm{N}(21) \cdots O \mathrm{O}(2), 2.891(10) \AA)$ to induce $P$-helical chirality with a $P-1,2^{\prime}$ helical conformation of the ferrocenoyl moiety, as shown in Figure 4a. The cleavage of the disulfide bond to the thiols was demonstrated to liberate the restriction of the cyclic dipeptide chain, resulting in the adoption of the preferred $P-1,2^{\prime}$ helical conformation by virtue of two rotatory $\mathrm{Cp}$ rings and the formation of intramolecular antiparallel $\beta$-sheet-like hydrogen bonds. Furthermore, an intramolecular hydrogen bond with a $\mathrm{N}-\mathrm{H} \cdot \cdots \mathrm{N}$ pattern between the $\mathrm{NH}$ of cystamine and the nitrogen of Pro (N(3) $\cdots \mathrm{N}(2), 2.751(11) \AA ; \mathrm{N}(23) \bullet \bullet N(22), 2.798(10) \AA)$ was formed, leading to lead the creation of a $\beta$-turn-like structure through weak intramolecular hydrogen bonding interactions between the $\mathrm{NH}$ of cystamine and the $\mathrm{CO}$ of the ferrocenoyl moiety $(\mathrm{N}(3) \cdots \mathrm{O}(1), 3.449(10) \AA ; \mathrm{N}(23) \cdots \mathrm{O}(21)$, $3.565(10) \AA)$ in each dipeptide chain. The torsion angles $\phi_{2}\left(\phi_{2}\right.$ $=-63.2(10)^{\circ}$ and $\left.\phi_{2} *=-67.2(10)^{\circ}\right), \psi_{2}\left(\psi_{2}=152.7(8)^{\circ}\right.$ and $\psi_{2} *$ $\left.=156.6(7)^{\circ}\right), \phi_{3}\left(\phi_{3}=74.2(10)^{\circ}\right.$ and $\left.\phi_{3} *=70.0(10)^{\circ}\right)$, and $\psi_{3}$ $\left(\psi_{3}=20.5(11)^{\circ}\right.$ and $\left.\psi_{3} *=26.7(11)^{\circ}\right)$ of $\mathbf{3}$ indicated a type II $\beta$ - turn-like structure (an ideal type II $\beta$-turn: $\phi 2=-60^{\circ}, \psi_{2}=120^{\circ}$, $\phi_{3}=80^{\circ}$, and $\psi_{3}=0^{\circ}$ ). It was found that thiol moieties introduced in the C-terminus of dipeptides did not participate in hydrogen bonding. An intermolecular hydrogen-bonding network was observed in the crystal packing of $\mathbf{3}$, in which each molecule is linked to four neighboring molecules (Figure S2 in the Supporting Information). An X-ray crystal structure analysis of the acyclic ferrocene-dipeptide conjugate $\mathbf{4}$ bearing two L-Ala-L-Pro- $\mathrm{NHCH}_{2} \mathrm{CH}_{2} \mathrm{SH}$ dipeptide chains revealed the chirality-organized structure of $P$-helical chirality with a $P-1,2^{\prime}$ helical conformation of the ferrocenoyl moiety through intramolecular antiparallel $\beta$-sheet-like hydrogen bonding between the $\mathrm{NH}$ group of Ala and the $\mathrm{CO}$ group of Ala (another chain) of each dipeptide chain $(\mathrm{N}(1) \cdots \mathrm{O}(22), 2.883(10) \AA$; $\mathrm{N}(21) \cdots \mathrm{O}(2), 2.952(9) \AA)$ as depicted in Figure 4b. An inverse $\gamma$-turn-like structure, as observed in the structure of the cyclic ferrocene-dipeptide conjugate 2 , was not formed in the acyclic ferrocene-dipeptide conjugate $\mathbf{4}$, probably due to the flexibility of the dipeptide chains. Intermolecular hydrogen bonds in the acyclic ferrocene-dipeptide conjugate $\mathbf{4}$ resulted in the induction of a right-handed helical molecular assembly in the crystal packing (Figure S3 in the Supporting Information).

To evaluate chirality-organized structures of the ferrocenedipeptide conjugates in the solution state, $\mathrm{CD}$ measurements were performed. An induced circular dichroism in the absorbance region of the ferrocene moiety was detected in the $\mathrm{CD}$ spectrum of the cyclic ferrocene-dipeptide conjugate $\mathbf{1}$ (Figure 5), while a negative Cotton effect at around $480 \mathrm{~nm}$ indicates $M$-helical chirality of the ferrocenoyl moiety. ${ }^{[2 f-g]}$ Electronic spectra of 1-4 are shown in Figures S4 and S5 in the Supporting Information. The chirality-organized structure as observed in the crystal structure was found to be preserved, even in solution. Preservation of the chirality-organized structure of $\mathbf{2}$ in solution was also supported by its CD spectrum 


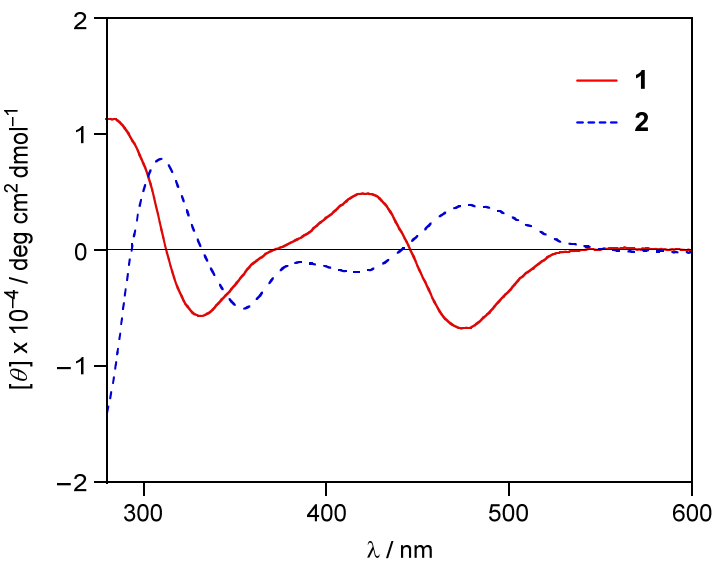

Figure 5. CD spectra of 1 in DMSO and 2 in dichloromethane $\left(1.0 \times 10^{-4}\right.$ $\mathrm{M})$.

which showed a positive Cotton effect at around $480 \mathrm{~nm}$ based on the $P$-helical chirality of the ferrocenoyl moiety (Figure 5). The ferrocenoyl moiety of the acyclic ferrocene-dipeptide conjugates 3 and $\mathbf{4}$ also had a $P$-helical chirlaity, as indicated by the appearance of a positive Cotton effect at around $480 \mathrm{~nm}$ in CD spectra, as shown in Figure 6.

In conclusion, the helical chirality of a series of ferrocenedipeptide bioorganometallic conjugates could be controlled by cyclic/acyclic conversion. The suitable regulation of the conformational flexibility allowed a type II $\beta$-turn-type second structure to be formed, thereby inducing $M$-helical chirality, which is oposite to that induced by all previously reported ferrocenedipeptide conjugates derived from 1,1'-ferrocenedicarboxylic acid. The absolute configuration of the remote amino acid also affected the induced chirality, and both $M$ - and $P$-chirality could be induced without changing the structure of the adjacent amino acid (i.e., 1 vs 2). Furthermore, the conversion of a type II $\beta$-turn-like structure to an antiparallel $\beta$-sheet-like structure was achieved through the reductive cleavage of the disulfide bond to thiol groups, leading to the conversion of $M$-helical chirality into $P$-helical chirality. The findings reported herein provide a new principle for designing artificial chiral assemblies. Applications of and the dynamic control of these chirality-organized structures and related conjugates are currently in progress.

Keywords: Ferrocene $\bullet$ Chirality control $\bullet$ Dipeptide $\bullet$ Hydrogen bond $\cdot$ Self-assembly

[1] a) R. H. Fish, G. Jaouen, Organometallics 2003, 22, 21662177; b) G. Jaouen, Bioorganometallics; Biomolecules, Labeling, Medicine. Wiley-VCH, Weinheim, 2006; c) C. G. Hartinger, P. J. Dyson, Chem. Soc. Rev. 2009, 38, 391-401; d) T. Hirao, T. Moriuchi, A. Gro $\beta$, Bioconjugates to Induce Chirality Organization. In: T. Hirao (Ed.), Functuionalized Redox Systems, Springer Japan, Japan, 2015, pp 111-150.

[2] a) R. S. Herrick, R. M. Jarret, T. P. Curran, D. R. Dragoli, M. B. Flaherty, S. E. Lindyberg, R. A. Slate, L. C. Thornton, Tetrahedron Lett. 1996, 37, 5289-5292; b) D. R. van Staveren, N. Metzler-Nolte, Chem. Rev. 2004, 104, 5931-5986; c) S. I. Kirin, H.-B. Kraatz, N. Metzler-Nolte, Chem. Soc. Rev. 2006,

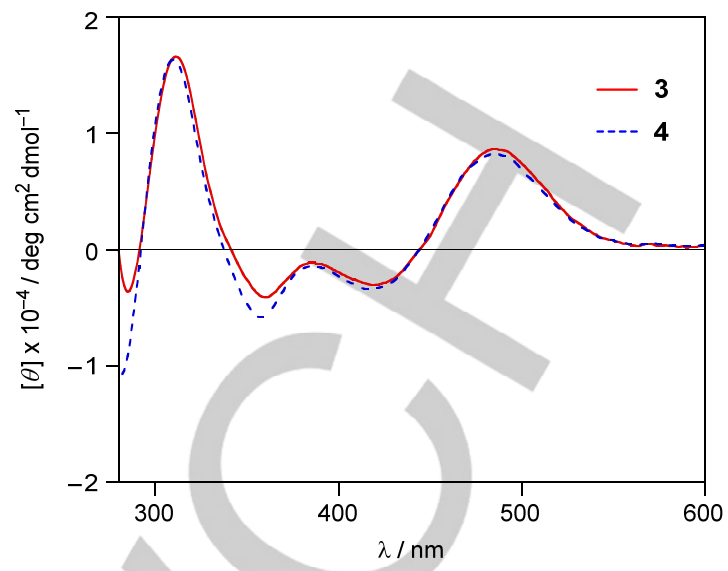

Figure 6. CD spectra of 3 and 4 in dichloromethane $\left(1.0 \times 10^{-4} \mathrm{M}\right)$.

35, 348-354; d) T. Moriuchi, T. Hirao, Ferrocene-Peptide Bioconjugates. In: G. Simonneaux (Ed.), Bioorganometallic Chemistry, Vol. 17. Springer-Verlag, Berlin Heidelberg, 2006, pp 143-175; e) M. Salmain, N. Metzler-Nolte, Bioorganometallic Chemistry of Ferrocene. In: P. Stepnicka (Ed.), Ferrocenes. John Wiley \& Sons, Chichester, 2008, pp 499-639; f) A. Lataifeh, S. Beheshti, H.-B. Kraatz, Eur. J. Inorg. Chem. 2009, 3205-3218; g) T. Moriuchi, T. Hirao, Acc. Chem. Res. 2010, 43, 1040-1051.

[3] a) A. Nomoto, T. Moriuchi, S. Yamazaki, A. Ogawa, T. Hirao, Chem. Commun. 1998, 1963-1964; b) T. Moriuchi, A. Nomoto, K. Yoshida, T. Hirao, J. Organomet. Chem. 1999, 589, 50-58; c) T. Moriuchi, A. Nomoto, K. Yoshida, A. Ogawa, T. Hirao, J. Am. Chem. Soc. 2001, 123, 68-75; d) T. Moriuchi, A. Nomoto, K. Yoshida, T. Hirao, Organometallics 2001, 20, 1008-1013; e) T. Moriuchi, K. Yoshida, T. Hirao, Organometallics 2001, 20, 3101-3105; f) T. Moriuchi, K. Yoshida, T. Hirao, J. Organomet. Chem. 2003, 668, 31-34; g) T. Moriuchi, K. Yoshida, T. Hirao, Org. Lett. 2003, 5, 42854288: h) T. Moriuchi, T. Nagai, T. Hirao, Org. Lett. 2005, 7 , 5265-5268; i) T. Moriuchi, T. Nagai, T. Hirao, Org. Lett. 2006, $8,31-34 ;$ j) T. Moriuchi, T. Nagai, T. Fujiwara, N. Honda, T. Hirao, Heterocycles 2008, 76, 595-603.

[4] a) S. Chowdhury, G. Schatte, H.-B. Kraatz, Dalton Trans. 2004, 1726-1730; b) S. Chowdhury, D. A. R. Sanders, G. Schatte, H.-B. Kraatz, Angew. Chem. Int. Ed. 2006, 45, 751754; c) S. Chowdhury, G. Schatte, H.-B. Kraatz, Eur. J. Inorg. Chem.. 2006, 988-993; d) C. C. G. Scully, P. Jensen, P. J. Rutledge, J. Organomet. Chem. 2008, 693, 2869-2876; e) C. Drexler, M. Milne, E. Morgan, M. Jennings, H.-B. Kraatz, Dalton Trans. 2009, 4370-4378.

[5] P. Demonchaux, A. Laayoun, M. Demeunynck, J. Lhomme, Tetrahedron 1989, 45, 6455-6466.

[6] D. S. Kemp, B. R. Bowen, Tetrahedron Lett. 1988, 29, 50815082.

[7] The detailed crystal data are summarized in Table S1 in the Supporting Information. CCDC-1486398 (1), CCDC1486400 (2), CCDC-1486401 (3), and CCDC-1486399 (4) contain the supplementary crystallographic data for this paper. These data can be obtained free of charge from The Cambridge Crystallographic Data Centre via www.ccdc.cam.ac.uk/data_request/cif. 
Entry for the Table of Contents (Please choose one layout)

Layout 2:

\section{COMMUNICATION}

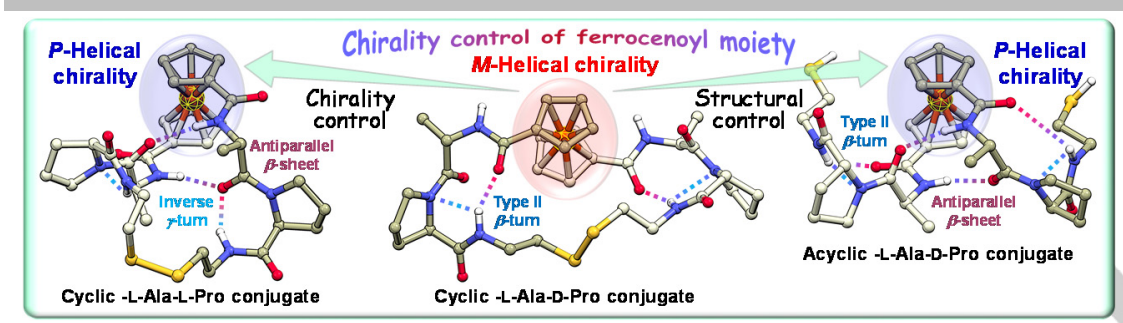

Controlling helical chirality and creating protein secondary structures in ferrocenedipeptide bioorganometallic conjugates were achieved by adjusting the conformational flexibility of the dipeptide chains. It is particularly interesting to note that M-helical chirality was produced in a cyclic ferrocene-dipeptide conjugate composed of the L-AlaD-Pro-cystamine-D-Pro-L-Ala dipeptide sequence, in which a type II $\beta$-turn-like secondary structure was established.
T. Moriuchi, ${ }^{*}$ T. Nishiyama, M. Nobu, and T. Hirao*

Page No. - Page No.

Control of Helical Chirality of Ferrocene-Dipeptide Conjugates by the Secondary Structure of Dipeptide Chains 